\title{
Information Sharing and Cooperative Search in
}

Fisheries

Keith S. Evans, Quinn Weninger

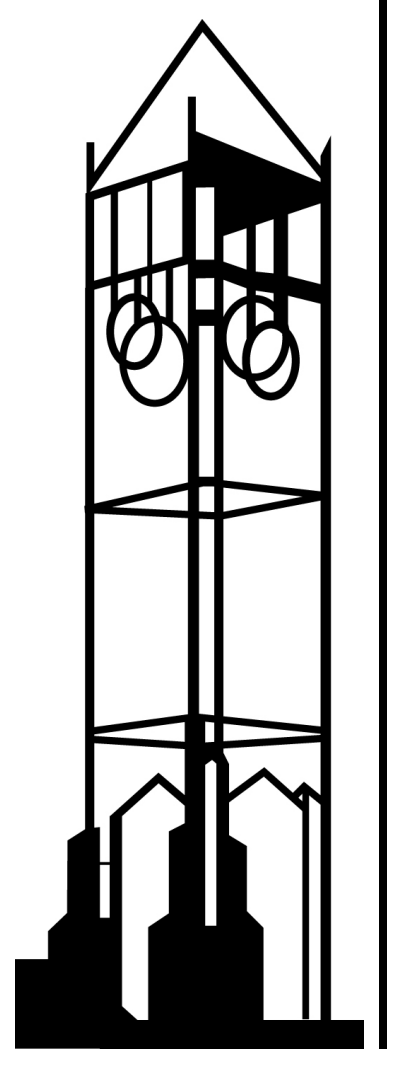

Working Paper No. 10014

June 2010

\section{IOWA STATE UNIVERSITY}

Department of Economics

Ames, lowa, 50011-1070

lowa State University does not discriminate on the basis of race, color, age, religion, national origin, sexual orientation, gender identity, genetic information, sex, marital status, disability, or status as a U.S. veteran. Inquiries can be directed to the Director of Equal Opportunity and Compliance, 3280 Beardshear Hall, (515) 294-7612. 


\title{
Information Sharing and Cooperative Search in Fisheries
}

\author{
March 28, 2013
}

\begin{abstract}
We present a dynamic game of search and learning about the productivity of competing fishing locations. Perfect Bayesian Nash equilibrium search patterns for noncooperating fishermen and members of an information sharing cooperative are compared with first-best outcomes. Independent fishermen do not internalize the full value of information, and do not replicate first-best search. A fishing cooperative faces a free-riding problem, as each coop member prefers that other members undertake costly search for information. Pooling contracts among coop members may mitigate, but are not likely to eliminate free riding. Our results explain the paucity of information sharing in fisheries and suggest regulators use caution in advocating cooperatives as a solution to common pool inefficiencies in fisheries.
\end{abstract}

Keywords: Search, information sharing, Bayesian learning, fisheries cooperatives. JEL codes: Q22, D8 


\section{Introduction}

Fishermen do not freely share valuable information. Anthropologists describe, instead, a culture of secrecy and deceit, where fishermen share only coarse (nondescript) information about the location of productive fishing sites (Palmer (1990), Gatewood (1984), and Andersen (1980)). Economists, on the other hand, have argued that information sharing can increase harvest productivity by avoiding redundant search and costly congestion on the fishing grounds (Costello and Polasky (2008), Wilen and Richardson (2008), Costello and Deacon (2007), and Wilson (1990)). Relative to their non-cooperating counterparts, Carpenter and Seki (2005) present empirical evidence of increased catch rates among Japanese shrimp fishermen who share information.

The two literatures present a puzzle: if information sharing is beneficial, why is it rare in the fishery? We wish to answer this question for more than curiosity's sake. First, understanding the motivation and possible barriers to information sharing may suggest policies that can harness the accompanying economic benefits identified by economists. Second, the role of fishing cooperatives has gained new importance in the design of fisheries management policy in the U.S. and elsewhere. Fishing cooperatives are viewed as one method to enhance property rights and address common-pool inefficiencies that plague fisheries resources. Understanding information exchange and coordination within a fishing cooperative is important for designing effective cooperative-based management.

We introduce a simple dynamic fishing game to examine the incentive for fishermen to undertake costly search for fish and share information. We compare Bayesian Nash equilibrium information acquisition under alternative institutional structures, ranging from independent fishermen to a stylized fishing cooperative that utilizes simple contracts to coordinate the activities of its members. Outcomes under each alternative are compared to coordinated search with full sharing of information, i.e., the first-best benchmark. We find that, relative to the first-best, non-cooperating fishermen gather too much (little) information when they believe its private cost to be low (high) relative to its private value. Divergence between privately optimal and first-best search arises because information value is not shared when fishermen do not cooperate, yet independent fishermen bear the full cost of gathering information.

Our results show that the benefits from information sharing are largest when congestion penalties are large, when information transmission among fishermen is costless, and when information about the true location of productive fishing sites does not quickly decay. A less obvious finding is the importance of free-riding. Our model emphasizes the role of active and costly information acquisition by fishermen. Steaming to an uncertain fishing site to learn about its true productivity utilizes fuel, labor, and bait, and importantly, 
implies time lost fishing at some other site. Once acquired, information is an excludable and non-rival good, or club good. To prevent free-riding, an information sharing group must distribute informational rents among its members, while maintaining incentives to undertake costly search for fish. We show how the extent of the free-riding problem depends on the contract used to distribute information acquisition costs and information rents among coop members. Devising contracts that result in optimal investment in information may be particularly challenging in fisheries, due to the club good characteristic of information, its costly acquisition, and the common property nature of the fishery resource.

Our results provide an explanation for the paucity of information sharing and coordination efforts in fisheries, and provide important insights for regulators. The 1998 American Fisheries Act facilitates the use of fishing cooperatives for strengthening property rights in fisheries. Fishing cooperatives are now established in several U.S. fisheries. ${ }^{1}$ An often cited benefit of cooperatives, one that is undocumented but regularly assumed, is that of free information exchange among members. For example, problems related to bycatch of undesirable or threatened stocks may be reduced if cooperating fishermen warn colleagues when and where a non-target stock is present. ${ }^{2}$ Our results suggest that policies that are based on presumption of free information flows within fishing cooperatives may fail to reduce bycatch, or address related management problems. We show which obstacles must be overcome before the information sharing benefits of fishing cooperatives will materialize.

Our paper is organized as follows. The next section presents further background on information sharing in fisheries. Section 3 presents our model and derives Perfect Bayesian Nash equilibrium outcomes. Section 4 summarizes the key findings and policy implications, and discusses extensions.

\footnotetext{
${ }^{1}$ According to U.S. Department of Agriculture (2012), there were 37 fishing cooperatives operating in the U.S. in 2010. See Kitts and Edwards (2003) for a discussion of U.S. legislation, the Fisheries Collective Marketing Act of 1934 and the American Fisheries Act of 1998, that allow the formation of fishing cooperatives.

${ }^{2}$ Management problems ranging from bycatch, to the design of marine protected areas have been linked to problems of information acquisition and information sharing in fisheries (Abbott and Wilen (2010), Marcoul and Weninger (2008), Costello and Deacon (2007), and Curtis and McConnell (2004)). The North Pacific Fishery Management Council (2011) discusses the use of fishing cooperatives in the Gulf of Alaska Pollock fishery to reduce incidental catch of Chinook salmon, stating cooperatives will "facilitate information sharing and fleet coordination that could be important to achieving Chinook avoidance (pp. 3, emphasis added)." Amendment 16 to the Northeast Multispecies Fisheries Management Plan pushes for expansion of the use of fishing cooperatives (New England Fishery Management Council (2010)).
} 


\section{Background}

Multiple theories have been offered for why fishermen may or may not share information. Wilson (1990) suggests fishermen discover productive fishing sites by chance and must then decide whether or not to divulge their location with members of a fishing club. He argues that information will be shared if the cost of doing so is not "too large." Wilson suggests that information sharing costs are low when the number of club members is small, when club members have small catching capacity, and when transaction costs accompanying information transmission are small. Wilson suggests further that the benefits of joining the information sharing club increase when club members are equally skilled at finding fish, and therefore are likely to reciprocate with valuable information at some future date.

The anthropology literature offers similar explanations for information sharing. Palmer (1990), Gatewood (1984), Orbach (1977), and others suggest fishermen will be more secretive when the direct cost of disclosing information is high. ${ }^{3}$

Information sharing and coordination is considered by economists to be beneficial, i.e., a profitable endeavor. Costello and Deacon (2007) suggest joining an information sharing group can prevent redundant search undertaken by independent fishermen (see also Wilson (1990)). A coalition of fishermen may benefit from specialization, with one or more members carrying out search activities while others specialize in harvesting fish (see also Marcoul and Weninger (2008)). Another motive for coordinating fishing activities is to avoid congestion costs that arise when multiple fishermen visit the same fishing site.

The role of cooperative behavior for addressing common-pool inefficiencies has been considered recently by several authors. Gilman et al. (2006) examine the effect of fleet communication programs on bycatch rates in a case study of three fisheries; the U.S. North Atlantic Longline Swordfish Fishery, the U.S. Alaska Demersal Longline Fisheries, and the U.S. North Pacific and Alaska Trawl Fisheries. The authors suggest that information sharing about bycatch "hotspots" helped reduce bycatch rates in the first two fisheries but that the evidence is unclear in the third. Haynie et al. (2009) find that groundfish fishermen in the Bering Sea act cooperatively to avoid halibut bycatch in order to extend the length of a target groundfish fishery, but that cooperation breaks down as the aggregate catch approaches the industry quota. Abbott and Wilen (2010) report similar findings for the Bering Sea groundfish fishery.

Heintzelman et al. (2009), observe that free-riding behavior in a partnership in which revenues are shared among members but costs are borne privately, can have the effect of

\footnotetext{
${ }^{3}$ Palmer (1990) finds that radio transmissions of Maine lobster fishermen convey detailed information about lobster size and fishing locations during pre-molting periods when lobster are hidden in rocks and less accessible to trap gear, i.e., information is shared when it has little value.
} 
mitigating the problem of overexploitation in common-pool resources. Kaffine and Costello (2011) find that spatial externalities can be eliminated under unitization, a form of cooperation where fishermen pool a portion of the profits they earn from exploiting spatially connected stocks. Our paper also considers cooperative behavior, although our focus is on information sharing and congestion of fishing grounds.

Finally, Holland (2010) and Holland and Jannot (2012) study catch and bycatch uncertainty in fisheries that are regulated with individual transferable quotas. The authors examine the role of risk pools, a type of fishing cooperative where individual fishermen pool quota holdings to manage unanticipated quota shortages and associated income loss. They find that risk pools can effectively mitigate income risk but caution against problems arising from adverse selection, i.e., attracting high risk fishermen into risk pools, and moral hazard, i.e., reducing incentives of individual members to undertake costly bycatch avoidance.

A common theme in earlier literature is that information sharing requires and is motivated by a quid pro quo arrangement; the hypothesis is that fishermen will voluntarily disclose information if and only if they receive information in return. But the criteria for forming an information sharing group must be more stringent. If there is to be a net gain from joining, it must be the case that expected profits per club member exceed the expected profits when fishermen act alone, i.e., there must be an information gathering return to scale, or information synergy as it have been termed in the literature (Gatewood (1984)). ${ }^{4}$ As will become clear in our analysis, we break from the quid pro quo paradigm and focus attention on the super-additive benefits of information sharing.

Previous literature has assumed fishermen are myopic, passive learners when making fishing site choices (e.g., Costello and Deacon (2007), Lynham (2006), and Smith (2000)). This assumption precludes costly investment in information and overlooks the free-riding problem. Myopic search may characterize search patterns in fisheries where information about the spatial-temporal distribution of the fish stock decays quickly. For example, pelagic species such as pacific tuna are highly mobile; knowledge of their current stock location may be a poor predictor of future location. On the other hand, the spatial distribution of many fish species can be linked to preferred marine habitat (MacCall (1990)). In this setting, knowledge of spatial-temporal distributions and movement is crucial for catch success. For example, fishermen in the pacific halibut longline fishery choose where and when to set

\footnotetext{
${ }^{4}$ Gatewood (1984) identifies an example of such a synergy in the Alaskan purse seine fishery, where managers tightly control the length of openings. The author notes that "While it is true that one boat can scout as wide an area in four days as four boats can in one day, the utility of the information collected by the four boats scouting the day before the opening is much greater, provided they share what each has observed (pp. 362)." It is important to note that the information gathering setting for salmon seiner's differs from the one that is modeled in this paper.
} 
gear based on acquired knowledge of the spatial distribution of the stock obtained primarily through exploration in the form of trial and error. ${ }^{5}$ Our model highlights the role of costly exploration and information sharing and therefore captures an important feature of the search process.

Lastly earlier studies of fishing cooperatives have ignored the internal governance structure of a fishing cooperative; a common assumption is that preferences of individual coop members coincide with those of a single decision making entity. First-best outcomes are assumed rather than tested. We relax this assumption and consider, explicitly, profit sharing arrangements among individual coop members who seek to maximize individual benefits of coop membership.

Our model will feature costly information acquisition and information sharing by risk neutral decision makers (see also Marcoul and Weninger (2008) and Mangel and Clark (1986)). While risk management may be an important motive in the formation of fishing cooperatives (Holland (2010); Holland and Jannot (2012)), risk aversion has confounding effects on the demand for information particularly in dynamic settings (Freixas and Kihlstrom (1984)). An analysis of the combined effects of information sharing and risk management under risk averse preferences is reserved for future work.

\section{Model}

Our model features the following elements: (1) extraction from a spatial commons, (2) uncertainty over true payoffs at competing fishing locations or sites, (3) the ability to learn about true productivity at competing sites, and (4) costly site congestion.

We introduce a two-period game played by two risk-neutral fishermen, $i=1$, 2 , who select from among two distinct fishing sites, $j=1,2$. To save on further notation, a prime is used to distinguish second period values; an absent prime indicates first period values.

The sequence of events in the fishing game is as follows. At date $t_{1}$ fishermen choose a fishing site based on their uncertain belief about payoffs at each site. First-period fishing yields a payoff realization, denoted $s_{i, j}$ for fisherman $i$ at site $j$. The payoff provides information, a noisy signal, about true payoff distribution at the fished site. Fishermen use first period information to update beliefs and then choose a second period fishing location (at date $t_{2}$ ). Second period fishing yields a second, final payoff realization. The fishermen's objective is to maximize the discounted sum of expected two-period payoffs. The second period payoff is discounted by a factor $\delta \in[0,1]$, which we assume is common across fishermen.

\footnotetext{
${ }^{5}$ Halibut are bottom fish that are not observable with sonar equipment; fishing success is not known until gear is soaked and retrieved and captured fish are counted.
} 
The payoff for fisherman $i$ at site $j$ takes the form,

$$
s_{i, j}=u_{j}+\varepsilon_{i, j},
$$

where $u_{j}$ is the unobservable true payoff at site $j$ and $\varepsilon_{i, j}$ is an idiosyncratic shock caused by random local weather or currents, or simply good or bad luck. We assume the distribution of $\varepsilon_{i, j}$ is known by the fisherman; $\varepsilon_{i, j} \stackrel{i i d}{\sim} N\left(0, \sigma^{2}\right)$, where $\sigma^{2}>0$ denotes signal variance. ${ }^{6}$

Fisherman uncertainty over payoffs at competing sites is represented as beliefs which follow a normal distribution. The current period belief for fishermen $i$ is summarized with parameters, $\left\{\mu_{i, j}, \sigma_{i, j}^{2}\right\}$ for $j=1,2$ where $\mu_{i, j}$ denotes the mean payoff and $\sigma_{i, j}^{2}$ denotes payoff variance. Current beliefs of the fisherman's counterpart are $\left\{\mu_{-i, j}, \sigma_{-i, j}^{2}\right\}$.

We will assume that signal noise and payoffs are independently distributed across sites, i.e., a payoff obtained from site $j$ provides information about true payoffs only at site $j .{ }^{7}$ Fishermen update beliefs about the true payoffs following Bayes' rule. Updating formulas are presented in Appendix A.

Players choose a single site in each period. If $a_{i}=1$ fishermen $i$ visits site 1 in the current period; $a_{i}=0$ denotes the case where fisherman $i$ visits site 2 in the current period. Mixed strategies are permitted. We assume fishing at some site is always preferred to not fishing at all. ${ }^{8}$

To ease notation and help fix ideas, much of our analysis will feature the cases of no discounting, $\delta=1$, and fully myopic fishermen, $\delta=0$. The implications of $\delta \in(0,1)$ are illustrated with a numerical example below.

We assume individual payoffs are reduced by a factor $\kappa \geq 0$ if both fishermen select the same site during a fishing period. $\kappa$ is assumed fixed and common across fishermen and sites. Alternate specifications for the congestion penalty were explored, e.g., site specific congestion penalties whose size was a function of the observed payoff signal $\left(\kappa_{j}=\kappa\left(s_{i, j}\right)\right)$. We found no qualitative change in the results and therefore maintain the simpler formulation.

Before turning to the analysis, a few words regarding our model setup and assumptions are warranted. First, we do not include stock dynamics or stock depletion in our model. Our unit of analysis is a site choice at the individual fisherman and trip level. At this scale, stock depletion can be assumed imperceptible since the harvest on a single trip represents a

\footnotetext{
${ }^{6}$ The assumption that $\varepsilon_{i, j}$ follows a known distribution simplifies the description of learning in the model, and is a standard component of Bayesian learning models (e.g., Marcoul and Weninger (2008); Mangel and Clark (1986)).

${ }^{7}$ The model can be extended to consider correlation in beliefs (Marcoul and Weninger (2008)). Correlated beliefs alter search behavior quantitatively. Our main insights regarding the efficiency of independent search and free riding within fishing coops do not change under correlated beliefs.

${ }^{8}$ Adding a third choice, "stay at port," complicates notation with few additional insights for information sharing.
} 
very small portion of the total exploitable biomass. On the other hand, fishing at site may cause localized, temporary stock depletion. Ecological models of the spatial distribution of fish stocks suggest that if fishing reduces stock density at a location, other fish will migrate to the location to take advantage of reduced competition for food and habitat. Natural ecological spatial equilibration of the fish stock causes the stock density to return, roughly, to its pre-fished level. Temporary local stock effects are captured by the congestion cost parameter in our model.

With multiple fishing periods, a component of the value of visiting a site is the information contained in the realized payoff. Much of the analysis that follows will focus on decisions to undergo costly exploration. We use the terminology investment in information to distinguish a site choice that pays, in the mind of the fisherman, a relatively lower expected payoff but yields high information value. To illustrate, suppose for a moment that there are no congestion costs. If $\mu_{i, 1}>\mu_{i, 2}$ and site 2 is chosen by fisherman $i$ in the first fishing period, it must be the case that the value of information from fishing site 2 offsets the perceived cost of obtaining the signal, which is equal to the foregone expected payoff, $\mu_{i, 1}-\mu_{i, 2}>0$. Note that a fisherman may choose a lower-expected-payoff site in the first fishing period to avoid congestion. This latter motive would not satisfy our definition of an investment in information.

The true distribution of the payoff at site $j$ is normal with mean $u_{j}$ and variance $\sigma^{2}$; the payoff variance arises because of unavoidable weather and fishing luck. However, because learning is incomplete and $u_{j}$ unknown, site choices must be based solely on beliefs; fisherman $i$ believes the payoff at site $j$ has mean $\mu_{j}$ and variance $\sigma_{i, j}^{2}+\sigma^{2}$. Expected payoffs at site $j$ are increasing in $\mu_{i, j}$ and non-increasing in the likelihood, a conjecture, that the rival will fish at the same site. Conjectures depend on beliefs about the beliefs, which is a standard feature of Bayesian games (Gibbons (1992)).

\subsection{First-best}

To characterize first-best site choices, we imagine a situation where a single manager directs each fisherman to a specific site in each period, with the goal of maximizing cumulative two-period, two-fishermen expected profit. The site choice problem is solved recursively. At date $t_{2}$, two payoff signals are available under three possible first-period scenarios: both fishermen fished at site 1 , both fished at site 2 , and each fished at a different site. In the following, we solve the first-best policy and payoffs for the case where both fishermen fished site 1. Analysis of remaining cases follows analogously and, to conserve space, is not repeated. As we are interested in the direction of fishing activity by a single manager, we 
drop the fisherman index $i$ where no confusion can arise.

At $t_{2}$, the manager compares expected payoffs for each site choice combination based on current period (updated) beliefs. The optimal policy takes a simple form,

$$
\left\{\begin{array}{lc}
a_{i}^{\prime}=a_{-i}^{\prime}=1 & \text { if } \mu_{1}^{\prime}-2 \kappa>\mu_{2}^{\prime} \\
a_{i}^{\prime}=a_{-i}^{\prime}=0 & \text { if } \mu_{1}^{\prime}<\mu_{2}^{\prime}-2 \kappa \\
a_{i}^{\prime}=1-a_{-i}^{\prime}=1 & \text { otherwise. }
\end{array}\right.
$$

It is convenient to express the above policy in terms of realized signals. Updated beliefs are linear functions of signals and therefore the policy in equation (1) is easily inverted. We divide site 1 signals into mutually exclusive subsets:

$$
\begin{aligned}
& S_{11}=\left\{\left(s_{i, 1}, s_{-i, 1}\right) \mid \mu_{1}^{\prime}-2 \kappa>\mu_{2}^{\prime}\right\} \\
& S_{22}=\left\{\left(s_{i, 1}, s_{-i, 1}\right) \mid \mu_{1}^{\prime}<\mu_{2}^{\prime}-2 \kappa\right\} \\
& S_{12}=\left\{\left(s_{i, 1}, s_{-i, 1}\right) \notin S_{11} \cup S_{22}\right\} .
\end{aligned}
$$

The expected payoffs for the two fishermen can then be written as,

$$
w^{\prime}\left(s_{i, 1}, s_{-i, 1}\right)=\left\{\begin{array}{cl}
2 \mu_{1}^{\prime}-2 \kappa & \text { if }\left(s_{i, 1}, s_{-i, 1}\right) \in S_{11} \\
2 \mu_{2}^{\prime}-2 \kappa & \text { if }\left(s_{i, 1}, s_{-i, 1}\right) \in S_{22} \\
\mu_{1}^{\prime}+\mu_{2}^{\prime} & \text { if }\left(s_{i, 1}, s_{-i, 1}\right) \in S_{12}
\end{array}\right.
$$

where the conditional dependence on initial beliefs is suppressed to conserve space. In the above expression, $w^{\prime}\left(s_{i, 1}, s_{-i, 1}\right)$ denotes the optimal aggregate, two-fisherman expected payoff, conditional on having obtained signals $\left(s_{i, 1}, s_{-i, 1}\right)$ in the first fishing period.

Now step back to the date $t_{1}$ site choice problem. Let $W_{j, k}$ denote the total two-period expected payoff from sending one fisherman to site $j$ and the other to site $k$ in the first period. Sending both to site 1 yields,

$$
W_{1,1}=2 \mu_{1}-2 \kappa+\delta E\left[w^{\prime}\left(s_{i, 1}, s_{-i, 1}\right)\right]
$$

where the expectation $E$ is conditional on date $t_{1}$ beliefs. Similarly, we have,

$$
\begin{aligned}
& W_{2,2}=2 \mu_{2}-2 \kappa+\delta E\left[w^{\prime}\left(s_{i, 2}, s_{-i, 2}\right)\right], \\
& W_{1,2}=\mu_{1}+\mu_{2}+\delta E\left[w^{\prime}\left(s_{i, 1}, s_{-i, 2}\right)\right] .
\end{aligned}
$$


The first-best expected payoff is then,

$$
W=\max _{j, k}\left\{W_{j, k}\right\} \quad j, k=1,2
$$

The model can be used to illustrate conditions under which investments in information are optimal. To demonstrate, assume beliefs satisfy $\sigma_{2}^{2}>\sigma_{1}^{2}$ and $\mu_{2}<\mu_{1}$. Site 2 is an uncertain site with a lower expected payoff than site 1 and thus sending a fishermen there to resolve some of the uncertainty implies a foregone expected payoff. If it is optimal to send one fisherman to the uncertain site it must be the case that $W_{1,2}>W_{1,1}$. This difference can be expressed alternatively as,

$$
\mu_{1}-\mu_{2}<\delta\left\{E\left[w^{\prime}\left(s_{i, 1}, s_{-i, 2}\right)\right]-E\left[w^{\prime}\left(s_{i, 1}, s_{-i, 1}\right)\right]\right\}+2 \kappa
$$

The left hand term in (3) is the perceived cost of sending one fisherman to the uncertain site. The first right hand term is the discounted expected value of information, i.e., a payoff signal, from the uncertain site 2 to guide site choices in the second fishing period. The final right hand term is the reduced congestion cost that results from sending fishermen to different sites. Expressed in this form, we see that sending one fisherman to a lower-expected-payoff site can be optimal even if the value of information is less than its cost. That is, if $\kappa$ is large, the gains from sending fishermen to different locations to avoid congestion can offset a reduction in expected payoff. On the other hand, from Marcoul and Weninger (2008) we know that for finite $\kappa$ there will exit a level of uncertainty at site 2 for which sending a fisherman to the lower expected payoff site is an optimal strategy. We also see that investments in information will not be undertaken by a myopic decision maker. Recall that our definition of investment in information requires that the value of information for improving future site choice, the first right-hand term in (3), offset the current period cost of gathering information. It is clear that when $\delta=0$ the only reason to send a fishermen to a lower-expected-payoff site is to avoid congestion cost.

\subsection{Independent fishermen}

We assume that independent fishermen choose sites simultaneously and non-cooperatively. To be consistent with the literature discussed in section 2, where fishermen share only coarse information, we assume that at date $t_{2}$, each observes the site that was fished by his counterpart in the first fishing period, but that realized payoffs are private information. To solve the model, we must specify what each fisherman believes about the beliefs of the other fish-

erman. We consider fishermen who have access to the same coarse information about the 
productivity of fishing sites (Wilson (1990)). While our model can accommodate different initial beliefs, a motivation for non-congruent initial beliefs is not obvious. We therefore solve for a symmetric perfect Bayesian Nash equilibrium (PBNE) assuming common prior beliefs at date $t_{1} \cdot{ }^{9}$ As above, the site choice problem is solved recursively.

Suppose fisherman $i$ chooses site $j$ in the first fishing period. Consider the following date $t_{2}$ strategy profile (we assume both fishermen play similar strategies),

$$
\begin{cases}\text { fish site } j & \text { if } s_{i, j}>s_{i}^{U} \\ a_{i}^{\prime} \in(0,1) & \text { if } s_{i}^{L} \leq s_{i, j} \leq s_{i}^{U} \\ \text { fish site } i & \text { if } s_{i, j}<s_{i}^{L}\end{cases}
$$

In the above expression, $s_{i}^{L}$ and $s_{i}^{U}$ demarcate regions of the signal space and can be explained with the help of an example. Suppose both fishermen fished site 1 in the first period. A fisherman who receives a high payoff at site 1 may favor a return trip. However, if both fishermen fished site 1, each must deduce that his opponent likely also received a high payoff, and therefore is also likely to return to the same sire in the second fishing period. This will result in congestion and reduced payoffs. The upper threshold $s_{i}^{U}$ is the payoff that is sufficiently large such that fisherman $i$ 's best strategy sets $a_{i}^{\prime}=1$, i.e., the fisherman returns to site 1 with certainty. In other words, a sufficiently high payoff from site 1 will lead to a return trip regardless of impending congestion cost. As intuition would suggest, $s_{i}^{U}$ is a non-decreasing function of congestion cost, $\kappa$.

By similar argument, a particularly low signal from site 1 favors a switch to site 2 in the second period. $s_{i}^{L}$ is the threshold signal at which fisherman $i$ 's best strategy sets $a_{i}^{\prime}=0$, i.e., the fisherman switches to site 2 with certainty. Upon receiving an intermediate payoff, the fisherman must deduce that his counterpart likely also received an intermediate payoff. Updated beliefs of both fishermen then suggest that congestion is likely, and therefore a mixed strategy is preferred. Derivation of the threshold values $s_{i}^{U}, s_{i}^{L}, s_{-i}^{U}$, and $s_{-i}^{L}$ is left to Appendix B.

The profile in equation (16) determines the $t_{2}$ site choice for all possible first period signals. The expected payoff at $t_{2}$, conditional on both fishermen fishing site 1 in the first period, is given as,

$$
v^{\prime}\left(s_{i, 1}, b\left(s_{-i, 1}\right)\right)= \begin{cases}\mu_{i, 1}^{\prime}-a_{-i}^{\prime} \kappa & \text { if } s_{i, 1}>s_{i}^{U} \\ \mu_{i, 2}^{\prime}-\left(1-a_{-i}^{\prime}\right) \kappa & \text { if } s_{i, 1}<s_{i}^{L} \\ a_{i}^{\prime}\left(\mu_{i, 1}^{\prime}-a_{-i}^{\prime} \kappa\right)+\left(1-a_{i}^{\prime}\right)\left[\mu_{i, 2}^{\prime}-\left(1-a_{-i}^{\prime} \kappa\right)\right] & \text { if } s_{i}^{L} \leq s_{i, 1} \leq s_{i}^{U},\end{cases}
$$

\footnotetext{
${ }^{9}$ The common prior is a standard assumption in the literature and a good starting point for our analysis. For a thorough description of the literature on the common prior assumption see Morris (1995).
} 
where the conditional dependence of beliefs on the observed signal $s_{i, 1}$ is dropped to conserve space. As $s_{-i, 1}$ is the private information of fisherman $i$ 's counterpart, the term $b\left(s_{-i, 1}\right)$ in $v(\cdot)$ captures $i$ 's best belief about $-i$ 's private information based on date $t_{2}$ updated beliefs. Expected payoffs at $t_{2}$ for other first period site choice combinations are derived similarly.

We now step back and consider date $t_{1}$ site choices. The strategy profile above outlines a best response for all first-period payoff realizations, and allows us to determine the twoperiod expected payoff for all site choice strategies. As an example, suppose both fishermen select site 1 at $t_{1}$. Let $V_{1,1}$ denote the expected payoff for a representative fisherman when both select site 1 in the first fishing period. We then have,

$$
V_{1,1}=\mu_{i, 1}-\kappa+\delta E\left[v^{\prime}\left(s_{i, 1}, b\left(s_{-i, 1}\right)\right)\right]
$$

The fisherman conditions his expected future payoffs on his best belief about the payoff signal observed by his rival. This knowledge is incorporated into his conjecture about the probable action of his rival in the second fishing period. The remaining cases are calculated similarly and take the form,

$$
\begin{aligned}
V_{1,2} & =\mu_{i, 1}+\delta E\left[v^{\prime}\left(s_{i, 1}, b\left(s_{-i, 2}\right)\right)\right], \\
V_{2,1} & =\mu_{i, 2}+\delta E\left[v^{\prime}\left(s_{i, 2}, b\left(s_{-i, 1}\right)\right)\right], \\
V_{2,2} & =\mu_{i, 2}-\kappa+\delta E\left[v^{\prime}\left(s_{i, 2}, b\left(s_{-i, 2}\right)\right)\right] .
\end{aligned}
$$

Using the conditional expected payoffs in equations (5) - (8), we can construct a $2 \times 2$ normal form representation of the date $t_{1}$ site choice game. The Perfect Bayesian Nash Equilibrium (PBNE) fishing strategy of this normal form game is,

$$
a_{i}=\left\{\begin{array}{cc}
1 & \text { if } V_{1,1}>V_{2,1} \text { and } V_{1,2}>V_{2,2} \\
0 & \text { if } V_{2,2}>V_{1,2} \text { and } V_{2,1}>V_{1,1} \\
\frac{V_{2,2}-V_{1,2}}{V_{1,1}-V_{2,1}+V_{2,2}-V_{1,2}} & \text { otherwise }
\end{array}\right.
$$

The maximum expected payoff for an independent fisherman is given as,

$$
V_{i}=a_{i}\left[a_{-i} V_{1,1}+\left(1-a_{-i}\right) V_{1,2}\right]+\left(1-a_{i}\right)\left[a_{-i} V_{2,1}+\left(1-a_{-i}\right) V_{2,2}\right]
$$

\subsection{Inefficiency of Independent Search}

This section contrasts PBNE and first-best site choice strategies over a range of initial beliefs about payoffs. We characterize inefficient search, which takes the form of over- or under-investment in information by independent fishermen. 


\section{FIGURE 1 HERE}

Figure 1 reports numerical solutions for the first-best (left-hand panels) and PBNE policies (right-hand panels), over a range of the belief space. ${ }^{10}$ Beliefs for which a visit to site 2 implies an investment in information are featured. The top panels report results for the baseline calibration. Panels in the second row report results for an increase in the congestion costs, third row panels consider an increase on the signal noise, and panels in the fourth row show results for an increase in the discount rate. Units on the horizontal axis are the ratio of mean payoffs $\mu_{i, 1} / \mu_{i, 2}$. Units on the vertical axis are the ratio of payoff uncertainty at site 2 relative to site $1, \sigma_{i, 2}^{2} / \sigma_{i, 1}^{2}$. Beliefs at the two sites are identical at the origin. Moving left to right raises the cost of investing in information at site 2 , and moving vertically corresponds to higher uncertainty at site 2 and thus a potentially increased upside value of investing in information.

Marcoul and Weninger (2008) show in a single agent model that for a given investment cost there will exist a threshold payoff uncertainty at which an investment in information becomes optimal. The equilibrium policies in Figure 1 illustrate this feature of the site choice problem. We have separated the belief space into regions. In region 0, no investments in information are made. Region 1 denotes beliefs for which a single investment in information is optimal and region 2 denotes beliefs for which two investments in information are made under the first-best policy. For non-cooperative fishermen, we calculate total investments in information as the sum of the probability that an investment is made. Region 1 is shown as the dashed line where $a_{i}+a_{-i}=1$. The expected payoffs of fishing strategies are continuous in beliefs, and thus investments in information exceed unity for beliefs to the north and west of the dashed line. Investments in information are less than unity for beliefs to the south and east of the dashed line.

To gain some intuition for the results, examine the first-best policy under the baseline parameters (results in the top left panel). For beliefs in region 2, both fishermen are sent to uncertain site 2 to gather information. This is optimal because the cost of collecting the information is low and the value of signals in terms of guiding second period site choice is high. As the cost of the information increases, moving left to right, or if uncertainty at site 2 is less, it is optimal to collect one signal from site 2. For beliefs in the south east region 0 , no investments in information are made as the costs outweigh the benefits.

Next, compare the first-best and PBNE results. The location and shape of the boundaries that define intensity of information investment differ. Region 2 (two investments in

\footnotetext{
${ }^{10}$ Though analytic solutions are preferred, two of the first-best expected payoff functions, $W_{1,2}$ and $W_{2,1}$, have no closed form solution. As such, we turn to numeric methods to analyze equilibrium search patterns and provide comparative dynamics on model parameters.
} 
information) is larger for non-cooperating fishermen, indicating over-investment in information relative to the first-best policy. The reason independent fishermen over-invest is that information, once gathered, is a public good that should be freely shared among the two fishermen. Because it is not in the independent case, redundant information and added cost are incurred relative to the first-best. This result confirms the insights of Costello and Deacon (2007), who suggest non-cooperation can lead to excessive or redundant search, alternatively, cooperation can eliminate excessive or redundant search for fish.

We see further that beliefs exist for which independent fishermen under-invest in information relative to the first-best policy. Region 0 (no information investment) is larger under the PBNE policy than under the first-best policy. The reason is that independent fishermen each incur the cost of gathering information, but do not share the benefit. When both fishermen benefit from information under the first-best, there exists a higher cost threshold at which information investment is optimal.

Second row panels reveal that higher congestion costs shrink regions 0 and 2, i.e, the belief space where both fishermen fish at the same site. Higher congestion costs expand the region of beliefs for which a single investment is optimal under the first-best policy. This result is not surprising since congesting a site is now more costly. The remaining results show that less information investment is undertaken when catch signal noise increases, and under a higher discount rate. These results are also expected. A comparison of the first-best and PBNE policies reveals, again, regions of the belief space where non-cooperating fishermen over- and under-invest in information relative to the first-best policy.

\subsection{Fishing cooperatives}

In the first-best analysis above, fishermen are directed to sites by a fictitious manager. This construct ignores crucial characteristics that distinguish cooperatives from ownerinvestor firms. Two that are of particular relevance for costly information gathering are decision rights within the organization, and the residual claims on earnings. In this section we consider simple but illustrative examples of internal governance structures that might be operational in a real-world fishing cooperative. Our goal is to illustrate some key challenges that must be overcome by the coop before the benefits of information sharing are realized. ${ }^{11}$

In the context of our model, the right to decide which site is fished by individual cooperative members will have important welfare and efficiency implications. In what follows

\footnotetext{
${ }^{11}$ Our approach follows the "new institutional economics" viewpoint, which emphasizes the role of transactions costs, property rights, and agency relationships for understanding organizational structure (Fama (1980), Williamson (1975), and Alchian and Demsetz (1972)). A comprehensive review of contracts that assign rights and residual claims within a fishing cooperative is beyond the scope of this paper. See Fama and Jensen (1983) for additional discussion of contracting in producer organizations.
} 
we do not consider a formal assignment of decision rights. Instead, we informally discuss the implications of decision rights such as majority rule or unanimous voting by cooperative members.

Suppose cooperative members are compensated for their fishing efforts under a piece-meal remuneration contract (Kaffine and Costello (2011), McConnell and Price (2006), Uchida and Wilen (2005)). Each fisherman receives a per-period payment, which we denote $\omega$, plus a share, $\alpha$, of the payoff realized at the site at which they fish. Under this scheme, the single-period payoff to fisherman $i$ from fishing at site $j$ is,

$$
\omega+\alpha s_{i, j}
$$

Following some preliminary analysis, we will consider a pooling arrangement where $\omega$ is determined by the aggregate payoffs earned by all cooperative members. ${ }^{12}$ This simple setup is general enough to capture egalitarian profit-sharing or full retention of the payoff at a fished site. We next show that a preference for exploitation over exploration will arise under a remuneration contract that allows fishermen to retain a disproportionate share of their realized fishing payoff.

\subsubsection{Site choice in a fishing cooperative}

Assume members of a fishing coop share common initial beliefs about payoffs distributions at competing sites and that these beliefs satisfy $\mu_{i, 1}>\mu_{i, 2}$ and $\sigma_{i, 1}^{2}<\sigma_{i, 2}^{2}$, where $i$ now indexes a representative member of the fishing coop. Coop members can solve for the first-best site choice policy, and agree that the first-best policy yields the highest expected payoff for the group. What is less clear is the mechanism that determines where each coop member will fish, how payoffs are distributed, and which internal governance structure can implement the first-best site choice policy.

Note first, that no tension will arise if the first-best policy sends both fishermen to the same site in period 1 since, in this case, each expects to receive the same two-period expected payoffs. We therefore focus on beliefs for which it is optimal for one fisherman to undertake a costly investment in information while the second exploits a higher expected payoff site. The question then becomes, which fisherman explores and which exploits?

In order to focus attention on site choices for the purpose of gathering information rather than coordination to avoid congestion costs, we will assume no congestion penalty occurs while fishing. With no congestion cost, the period 2 payoff will be the same for both coop

\footnotetext{
${ }^{12}$ The pooling of profit, revenue, and/or cost is common among existing fishing cooperatives; see Uchida and Baba (2008), Knapp (2008), Gaspart and Seki (2003) for examples.
} 
members since both will fish at the highest expected payoff site in period 2. Lastly, suppose $\omega$ is set such that the coop balances its budget in each period. Under these assumptions each member retains an $\alpha$ share of his own first-period realized payoff and the residual that is re-distributed (equally) to each member is $(1-\alpha)\left(s_{i, 1}+s_{-i, 2}\right)$. We also see that,

$$
\omega=\frac{1-\alpha}{2}\left(s_{i, 1}+s_{-i, 2}\right)
$$

Simple algebra finds that the first period expected payoff for the fisherman who exploits site 1 is,

$$
\frac{1}{2}\left(\mu_{i, 1}+\mu_{i, 2}\right)+\frac{\alpha}{2}\left(\mu_{i, 1}-\mu_{i, 2}\right)
$$

whereas, the expected payoff for the fisherman who undertakes costly exploration at site 2 expects payoff,

$$
\frac{1}{2}\left(\mu_{i, 1}+\mu_{i, 2}\right)-\frac{\alpha}{2}\left(\mu_{i, 1}-\mu_{i, 2}\right) .
$$

These expressions illustrate that for $\alpha>0$, each coop member will prefer that some other member be responsible for costly investment in information. Each member has an incentive to free-ride on the costly search efforts of others. Full profit sharing will remove preference for exploitation over exploration since when $\alpha=0$ the expected payoffs in (9) and (10) are equal. However, profit sharing combined with unobservable effort and costs may create a moral hazard problem (Holland and Jannot (2012)). It is reasonable to presume that while harvest is observed at the dock, the allocation of effort and therefore costs that are allocated at sea in remote areas, are largely private information. With full profit sharing, each coop member will have incentive to overstate costs to increase his/her share of total coop earnings. This may explain why piece-meal contracts (with $\alpha>0$ ) are observed in fishing cooperatives (Uchida and Baba (2008), Knapp (2008), Costello and Deacon (2007), and Gaspart and Seki (2003)).

A broader question is how free-riding impedes the cooperative's ability to implement first-best site choices. The issue here is the extent to which the internal distribution of information rents and private costs of gathering information may distort coordination of site choices. To demonstrate, the top panel (a) of Figure 2 shows the two-period expected payoffs under the first-best policy as a function of the cost of gathering information. The bottom panel (b) of Figure 2 shows expected payoffs when individual coop member remuneration follows a piece-meal contract with $\alpha>0$. Uncertainty is fixed at $\sigma_{i, 1}^{2}<\sigma_{i, 2}^{2}$; as above site 2 plays the role of the uncertain site at which an investment in information may occur. Units on the horizontal axis are $\mu_{i, 1}-\mu_{i, 2}$ and measure the cost, in absolute terms, of gathering information at uncertain site 2 . Costs increase moving left to right in the figure. 


\section{FIGURE 2 HERE}

The panel (a) in Figure 2 shows two period expected payoffs under the first best policy; $W_{1,1}$, is the expected payoff from sending two fishermen to site 1 and $W_{1,2}$ is expected payoff from sending one fisherman to each site. The first best payoff is the upper envelope of the two curves. Thus, first best site choice requires one fishermen fish at uncertain site 2 for information costs less than $f$. For costs exceeding $f$, it is optimal for both fishermen to fish at site 1 .

The bottom panel (b) shows two-period expected payoffs for a two-fisherman coop; $V_{1,1}^{c}$ is the expected payoff for a representative coop member when both members fish at site 1; $V_{2,1}^{c}$ is the expected payoff for a representative member who undertakes costly exploration at the uncertain site 2 and is paid under the piece-meal contract discussed above; $V_{1,2}^{c}$ is the expected payoff for an individual coop member who exploits the higher-expected payoff site. Panel (b) illustrates the internal conflict and the free riding incentive operating within the cooperative. The exploiting fisherman benefits from an investment in information at all information costs below $g$. For beliefs in this range, the exploiting fisherman is therefore likely to support a decision to have some other coop member gather information at site 2 . A coop member who is asked to explore the uncertain site will agree only if costs are in the range 0 to $e$. At costs exceeding $g$ the optimal policy sends both fishermen to site 1 and the problem of deciding which fishermen will undertake costly exploration does not arise. However, for costs between $e$ and $g$ conflict over site assignments and the residual claims on earnings will exist.

Whether this conflict leads to inefficient search will depend on the decision process used to direct members to alternate sites. For example, suppose there are more than two fishermen in the cooperative. If site choices are determined by a majority vote of coop members, investments in information with costs in the range $e-g$ will be determined democratically; a potential over-investment in information could occur for costs between $f$ and $g$. The reason is that non-exploring coop members benefit from information and may be willing for vote in favor depending on the division of rents within the organization. If individual coop members pay less than the full information cost, a vote in favor of excess and inefficient information gathering could prevail. On the other hand, suppose each fisherman has veto power over the collective site choice plan. In this case, exploration may occur only for costs in the range 0 to $e$. This is because individual members who perceive a private cost may oppose a plan in which they earn a reduced share of collective payoffs. In sum, site choices that are determined by a group of voting members may diverge from the first-best plan causing inefficiency search and reduced payoffs compared to the first best.

Can the piece-meal contract be modified to remedy the free-riding problem? Suppose, 
for example, a fee is charged to fishermen who are the net beneficiaries of investments in information, and a subsidy is paid to fishermen who bear the burden of a costly search. In order for fishermen to be indifferent between exploration and exploitation, the first-period remuneration must be equalized. From equations (9) and (10) we find that the fee collected from the exploiting fishermen, that is transferred to the exploring fishermen, must fully offset the retained profits at each fishing site. In other words, the fee and subsidy must counter the effect of the residual claim on realized fishing payoffs. A system of fees and subsidies that removes the free-riding problem and reproduces the first-best must correspond to the case of $\alpha=0$, i.e., fishermen remuneration is independent of the realized fishing payoffs at the sites at which they fish.

\subsubsection{Gains from coop membership}

Our model can shed light on the decision of independent fishermen to join an information sharing coop. In practice, participation in fishing cooperatives is voluntary. It is reasonable to assume that an independent fishermen will join the coop only if they perceive a net gain from membership.

\section{FIGURE 3 HERE}

To illustrate, consider Figure 3, which presents the expected payoffs for an independent fishermen, $V_{i}$, and the average expected payoff to a coop member under first-best site choices, $\bar{V}^{c}$, as a function of information gathering cost. As above, site 2 plays the role of lowerexpected payoff but a higher payoff variance site. The figure also shows expected payoffs if coop members follow the first-best site choice, but are assigned roles and paid under the piece-meal contract discussed above $(\alpha>0) ; V_{\text {explore }}^{c}$ is the expected payoff for a member charged with costly exploration whereas $V_{\text {exploit }}^{c}$ is the expected payoff for a member who exploits the higher payoff site.

Since information sharing within a coop yields positive value, the figure shows $\bar{V}^{c}>V_{i}$. The kink in $V_{i}$ at point $d$ delineates the highest cost that an independent is willing to pay to gather information at the uncertain site 2 . The value of information, once collected, benefits all coop members, and thus the highest cost that prompts information gathering within the coop is greater than $d$ in the figure.

Comparison of the coop member and independent fisherman payoffs reveals several insights. First, the payoff difference depends on beliefs with the gains from coop membership greatest when the cost of gathering information is low. At low costs, fishing site 2 is attractive to both the coop member and the independent fisherman. However, operating within the cooperative further enhances the benefit of information, since information is shared between members. When the cost of gathering information at uncertain site 2 becomes excessive, 
neither the coop nor the independent fishermen invest in information and the gains from coop membership, which on average are given as $\bar{V}^{c}-V_{i}$, become smaller.

If a piece-meal remuneration contract is used to distribute payoffs within the coop, the gains from membership depend on the perceived role within the coop. The gain from membership is largest for exploiting coop members and smallest for exploring coop members. ${ }^{13}$

Other factors not considered in our model may also affect the potential net gain of membership in fishing cooperatives. Internal administrative and monitoring costs, for example, will raise coop costs, and lower the expected gains from membership. More generally, agency problems which are not a factor for independent fisherman are likely to reduce the relative difference between $\bar{V}^{c}, V_{\text {explore }}^{c}$, and $V_{\text {exploit }}^{c}$ and $V_{i}$.

Lastly, the curves in Figure 3 illustrate one example of the relationship between coop and independent fishermen payoffs. Congestion costs, signal noise, discount rates, risk preferences, decision rights, and the distribution of fishing profits among coop members will influence expected payoffs under both institutional relationships and the gains from coop membership.

\section{Conclusions}

We have introduced a dynamic game of information sharing in a fishery with uncertainty about payoffs at competing fishing sites. We contrast first-best and non-cooperative site choice policies over various model parameters. We show that privately optimal investments in information by non-cooperating fishermen diverge from first-best investment over a range of beliefs about true payoffs at competing sites. Our results confirm that non-cooperating fishermen engage in redundant and inefficient search when the private cost of gathering information is perceived to be low (Costello and Deacon (2007)). Non-cooperating fishermen under-invest in information relative to the first-best when the private cost of information is perceived to be high. The simple intuition for the divergence between the Perfect Bayesian Nash Equilibrium policies we study and first-best outcomes is that information, once collected and shared, is a public good that can benefit all fishermen. When information is shared among a group of cooperating fishermen, a lower benefit threshold is required before costly information gathering is warranted.

Our analysis shows that while fishermen can benefit from sharing information about productive fishing sites and coordinating site choices to avoid congestion, free-riding problems

\footnotetext{
${ }^{13}$ The shape and location of $\bar{V}^{c}$ and $V_{i}$ will also depend on beliefs. Our numerical simulations reveal that $V_{i}$ can exceed $\bar{V}^{c}$ over some regions of the belief space. This result arises because information, which is more available in a coop, lowers belief variance, which implies lower probability of extreme high payoff outcomes.
} 
can detract from the potential gains. We show how the level of efficiency attained in a cooperative of fishermen will depend on the internal governance structure of the organization. Remuneration schemes must be designed to distribute information rents while maintaining incentives to undertake costly search if first-best search outcomes and payoffs are to be achieved. Devising such schemes may be particularly challenging in fisheries, e.g., eliminating free-riding problems may be inconsistent with performance-based remuneration schemes. Egalitarian profit-sharing can overcome the free-riding problem, but requires full disclosure and is likely to require costly monitoring of costs of individual coop members. Profit sharing may also exacerbate agency costs which can detract from the overall performance of a fishing cooperative.

Extensions of the current analysis to formally study membership decisions under an endogenous contract design and strategic information disclosure may provide additional insights and explanations for the paucity of information sharing in fisheries. In particular, deceit is common among commercial fishermen (Palmer (1990), Gatewood (1984), and Andersen (1980)). Identifying conditions under which truth-telling is an equilibrium strategy in an information sharing game could provide additional insight.

It is now recognized that solutions to global depletion of marine fish stocks will likely require some form of strengthened property rights for resource users (Costello et al. (2008)). Fishing cooperatives are considered a form of enhanced property rights, capable of addressing various inefficiencies that plague common-pool resources (National Oceanic and Atmospheric Administration (2010)). Cooperatives are being considered as potential solutions to other management problems, including bycatch of unwanted species (North Pacific Fishery Management Council (2011)). Our results suggest that the ability of fishing cooperatives to remedy fishery management problems requires further study. Forming a cooperative does not guarantee a solution to common pool inefficiencies and may increase free-riding and other agency problems and costs (see also Holland and Jannot (2012)). Our results offer insights that may help policy makers design more effective regulations in marine fisheries.

\section{References}

Abbott, J., Wilen, J. E., 2010. Voluntary Cooperation in the Commons? Evaluating the Sea State Program with Reduced Form and Structural Models. Land Economics 86 (1), $131-154$.

Alchian, A., Demsetz, H., 1972. Production, Information Costs, and Economic Organization. American Economic Review 62 (5), 777-795. 
Andersen, R., 1980. Secrecy: A Cross-Cultural Perspective. Human Science Press, Ch. Hunt and Conceal: Information Management in Newfoundland Deep-Sea Trawler Fishing, pp. $205-228$.

Carpenter, J., Seki, E., 2005. Do Social Preferences Increase Productivity? Field Experimental Evidence from Fishermen in Toyama Bay. IZA DP No. 1697, Institute for the Study of Labor (IZA).

Costello, C., Deacon, R., 2007. The Efficiency Gains from Fully Delineating Rights in an ITQ Fishery. Marine Resource Economics 22 (4), 347-361.

Costello, C., Gaines, S. D., Lynham, J., 2008. Can Catch Shares Prevent Fisheries Collapse? Science 321 (5896), 1678-1681.

Costello, C., Polasky, S., 2008. Optimal Harvesting of Stochastic Spatial Resources. Journal of Environmental Economics and Management 56 (1), 1-18.

Curtis, R. E., McConnell, K. E., 2004. Incorporating Information and Expectations in Fishermen's Spatial Decisions. Marine Resource Economics 19, 131-143.

Fama, E. F., 1980. Agency Problems and the Theory of the Firm. Journal of Political Economy 88, 288-307.

Fama, E. F., Jensen, M. C., 1983. Separation of Ownership and Control. Journal of Law and Economics XXVI, 301-325.

Freixas, X., Kihlstrom, R., 1984. Bayesian Models in Economic Theory. Elsevier, Ch. Risk Aversion and Information Demand, pp. 93-104.

Gaspart, F., Seki, E., 2003. Cooperation, Status Seeking and Competitive Behaviour: Theory and Evidence. Journal of Economic Behavior and Organization 51 (1), 51-77.

Gatewood, J., 1984. Cooperation, Competition, and Synergy: Information-Sharing Groups Among Southeast Alaskan Salmon Seiners. American Ethnologist 11 (2), 350-370.

Gibbons, R., 1992. Game Theory for Applied Economists. Princeton University Press.

Gilman, E. L., Dalzell, P., Martin, S., 2006. Fleet Communication to Abate Fisheries Bycatch. Marine Policy 30, 360-366.

Haynie, A. C., Hicks, R. L., Schnier, K. E., 2009. Common Property, Information, and Cooperation: Commercial Fishing in the Bering Sea. Ecological Economics 69, 406-413. 
Heintzelman, M., Salant, S. W., Schott, S., 2009. Putting Free-Riding to Work: A Partnership Solution to the Common-Property Problem. Journal of Environmental Economics and Management 57, 309-320.

Holland, D., 2010. Markets, Pooling and Insurance for Managing Bycatch in Fisheries. Ecological Economics 70, 121-133.

Holland, D., Jannot, J. E., 2012. Bycatch Risk Pools for the us West Coast Groundfish Fishery. Ecological Economics 78, 132-147.

Kaffine, D. T., Costello, C., 2011. Utilization of Spatially Connected Renewable Resources. The BE Journal of Economics Analysis \& Policy 11, Article 15 (Contributions).

Kitts, A., Edwards, S., 2003. Cooperatives in U.S. Fisheries: Realizing the Potential of the Fishermen's Collective Marketing Act. Marine Policy 27, 357-366.

Knapp, G., 2008. Case Studies in Fisheries Self-Governance. Ch. The Chignik Salmon Cooperative, pp. 335-348, FAO Fisheries Technical Paper No. 504.

Lynham, J., 2006. Schools of Fishermen: A Theory of Information Sharing in Spatial Search, Department of Economics, UCSB Working Paper.

MacCall, A. D., 1990. Dynamic Geography of Marine Fish Populations. University of Washington Press.

Mangel, M., Clark, C., 1986. Search Theory in Natural Resource Modeling. Natural Resource Modeling 1, 1-54.

Marcoul, P., Weninger, Q., 2008. Search and Active Learning with Correlated Information: Empirical Evidence from Mid-Atlantic Clam Fishermen. Journal of Economic Dynamics and Control 32 (6), 1921-1948.

McConnell, K., Price, M., 2006. The Lay System in Commercial Fisheries: Origin and Implications. Journal of Environmental Economics and Management 51 (3), 295-307.

Morris, S., 1995. The Common Prior Assumption in Economic Theory. Economics and Philosophy 11, 227-253.

National Oceanic and Atmospheric Administration, 2010. National Oceanic and Atmospheric Administration (NOAA) Catch Share Policy. Available online: http://www.nmfs.noaa.gov/sfa/domes_fish/catchshare/index.htm. 
New England Fishery Management Council, 2010. New England Fisheries Management Council (NEFMC): Final Amendment 16 to the Northeast Multispecies Fishery Management Plan. Available online: http://www.nefmc.org/nemulti/index.html.

North Pacific Fishery Management Council, 2011. (NPFMC) Discussion Paper on Cooperatives: Gulf of Alaska Chinook Salmon Bycatch. Available online at: http://www.fakr.noaa.gov/npfmc/current_issues/bycatch/211GOAChinookCoops.pdf.

Orbach, M. K., 1977. Hunters, Seamen, and Entrepreneurs : The Tuna Seinermen of San Diego. Berkeley: University of California Press.

Palmer, C. T., 1990. Telling the Truth (up to a point): Radio Communication among Maine Lobstermen. Human Organization 49 (2), 157-163.

Smith, M., 2000. Spatial Search and Fishing Location Choice: Methodological Challenges of Empirical Modeling. American Journal of Agricultural Economics 82 (5), 1198-1206.

Uchida, H., Baba, O., 2008. Case Studies in Fisheries Self-Governance. Ch. Fishery Management and the Pooling Arrangement in the Sakuraebi Fishery in Japan, pp. 175-189, FAO Fisheries Technical Paper No. 504.

Uchida, H., Wilen, J. E., 2005. Harvester Cooperative, Pooling Arrangements and Market Power, Department of Agriculture and Resource Economics, UC Davis Working Paper.

U.S. Department of Agriculture, 2012. United States Department of Agriculture: Business and Cooperative Programs: Number of Cooperatives \& Memberships by Major Business Activities 2009. Available online: http://www.rurdev.usda.gov/rbs/coops/data.htm.

Wilen, J. E., Richardson, E. J., 2008. Case Studies in Fisheries Self-Governance. Ch. Rent Generation in the Alaskan Pollock Conservation Cooperative, pp. 261-368, FAO Fisheries Technical Paper No. 504.

Williamson, O., 1975. Markets and Hierarchies: Analysis and Antitrust Implications. The Free Press.

Wilson, J., 1990. Fishing for Knowledge. Land Economics 66 (1), 12-29. 


\section{A Belief Updating}

Three belief updating scenarios are possible in this model: no signal, one signal, or two signals about the profitability of a fishing site. Under the independence assumption - payoffs across sites are independent - a signal from site $k$ provides no new information about site $j$. As such, updated beliefs at site $j$ equal the prior belief, regardless of the information observed in the signal $s_{i, k}$.

Suppose, instead, that a single signal from site $j$ is observed. For prior beliefs $\mu_{i, j}, \sigma_{i, j}^{2}$, and single payoff signal $s_{i, j}$, the updated beliefs of fisherman $i$ at site $j$ are given as,

$$
\begin{aligned}
& \mu_{i, j}^{\prime} \mid s_{i, j}=\theta_{i, j} \mu_{i, j}+\left(1-\theta_{i, j}\right) s_{i, j} \\
& \sigma_{i, j}^{2^{\prime}} \mid s_{i, j}=\theta_{i, j} \sigma_{i, j}^{2},
\end{aligned}
$$

where $\theta_{i, j}=\sigma^{2} /\left(\sigma^{2}+\sigma_{i, j}^{2}\right) \in[0,1]$ weights the new information contained in the signal against prior beliefs. As uncertainty is resolved, more weight is placed on the prior.

Suppose now that two signals are available to fisherman $i$ from site $j$; one from fisherman $i$ and the other from $-i$. Then updated beliefs at $j$ are given as,

$$
\begin{aligned}
\mu_{i, j}^{\prime} \mid s_{i, j}, s_{-i, j} & =\theta_{i, j} \mu_{i, j}+\left(1-\theta_{i, j}\right) \bar{s}_{j} \\
\sigma_{i, j}^{2^{\prime}} \mid s_{i, j}, s_{-i, j} & =\theta_{i, j} \sigma_{i, j}^{2}
\end{aligned}
$$

where $\bar{s}_{j}$ denotes the average payoff signal observed at site $j$ and $\theta_{i, j}=\sigma^{2} /\left(\sigma^{2}+2 \sigma_{i, j}^{2}\right) \in[0,1]$ again weights the new information (from two signals) against prior beliefs.

\section{B Bayesian Nash Equilibrium}

This sections solves the date $t_{2}$ Bayesian game for independent risk neutral fishermen. We solve for the thresholds $s_{i}^{U}, s_{i}^{L}, s_{-i}^{U}$, and $s_{-i}^{L}$ from (16), which separate feasible signals into regions. There are four possible scenarios to consider depending on the period 1 site choices. We present the calculations for the case where both fishermen fish site 1 in the first fishing period. The analysis of the remaining cases follows analogously and is not repeated.

We begin by specifying how fishermen form beliefs about beliefs. Since both fishermen fished site 1 in the first period, $i$ 's belief about $-i$ 's private information should be a function of $s_{i, 1}$, i.e., $i$ 's private information obtained from fishing site 1 . The best information available about $-i$ 's beliefs comes from $i$ 's updated beliefs. As such, each fisherman believes they share the same updated beliefs about sites 1 and 2 .

Suppose $s_{-i}^{U}$ and $s_{-i}^{L}$ exist such that the representative fisherman's counterpart plays the 
strategy outlined in equation (16). For the representative fishermen with $s_{i, 1} \in\left[s_{i}^{L}, s_{i}^{U}\right]$ to play a mixed strategy in $t_{2}, a_{i}^{\prime} \in(0,1)$, it must be the case that, based on his conjecture about his counterpart's strategy, he is indifferent between fishing site 1 and site 2. Setting the expected payoff of fishing these sites equal and solving for $a_{-i}^{\prime}$ finds,

$$
a_{-i}^{\prime}=\frac{\mu_{i, 1}^{\prime}-\mu_{i, 2}^{\prime}-\kappa+2 \kappa \operatorname{Pr}\left(s_{-i, 1}<s_{-i}^{U} \mid s_{i, 1}\right)}{2 \kappa \operatorname{Pr}\left(s_{-i}^{L} \leq s_{-i, 1} \leq s_{-i}^{U} \mid s_{i, 1}\right)} \quad \forall s_{i, 1} \in\left[s_{i}^{L}, s_{i}^{U}\right]
$$

Using the same method, we can calculate the mixed fishing strategy for the representative fisherman, $a_{i}^{\prime}$.

In a BNE, each player's action must be optimal subject to their Bayesian updated belief about the strategy of their rival. Using $a_{i}^{\prime}$ and $a_{-i}^{\prime}$, we derive four equations that define the parameters $s_{i}^{U}, s_{i}^{L}, s_{-i}^{U}$, and $s_{-i}^{L}$ that will satisfy a BNE.

The representative fisherman believes that his counterpart is indifferent between mixing and fishing site 1 when $a_{-i}^{\prime}$ exactly equals one (his counterpart knows that this is the representative fisherman's belief). For site 1 to be strictly dominant, it must be that it is still preferred even under the worst case (when both fish the site). Using this fact, the updating rules in Appendix A, and the strategy profile in equation (16), the representative fisherman's upper signal threshold $s_{i}^{U}$ must satisfy

$$
s_{i}^{U}=\frac{1}{1-\theta_{i, 1}}\left\{\mu_{i, 2}-\theta_{i, 1} \mu_{i, 1}+\kappa\right\}
$$

where $\theta_{i, 1}=\sigma^{2} /\left(\sigma^{2}+\sigma_{i, 1}^{2}\right)$.

Similarly, fisherman $i$ believes his counterpart is indifferent between mixing and fishing site 2 when $a_{-i}$ exactly equals zero (his counterpart knows that this is the representative fisherman's belief). For site 2 to be strictly dominant, it must be that it is still preferred even under the worst case (when both fish the site). Using this fact and given the strategy profile, the representative fisherman's lower signal threshold $s_{i}^{L}$ must satisfy

$$
s_{i}^{L}=\frac{1}{1-\theta_{i, 1}}\left\{\mu_{i, 2}-\theta_{i, 1} \mu_{i, 1}-\kappa\right\}
$$

Using the same argument, we construct the following for fisherman $-i$ :

$$
\begin{aligned}
& s_{-i}^{U}=\frac{1}{1-\theta_{-i, 1}}\left\{\mu_{-i, 2}-\theta_{-i, 1} \mu_{-i, 1}+\kappa\right\} \\
& s_{-i}^{L}=\frac{1}{1-\theta_{-i, 1}}\left\{\mu_{-i, 2}-\theta_{-i, 1} \mu_{-i, 1}-\kappa\right\} .
\end{aligned}
$$


The thresholds that satisfy the BNE $, s_{i}^{U}, s_{i}^{L}, s_{-i}^{U}$, and $s_{-i}^{L}$, defined by equations (18) (21), must simultaneously hold. 


\section{Figures}
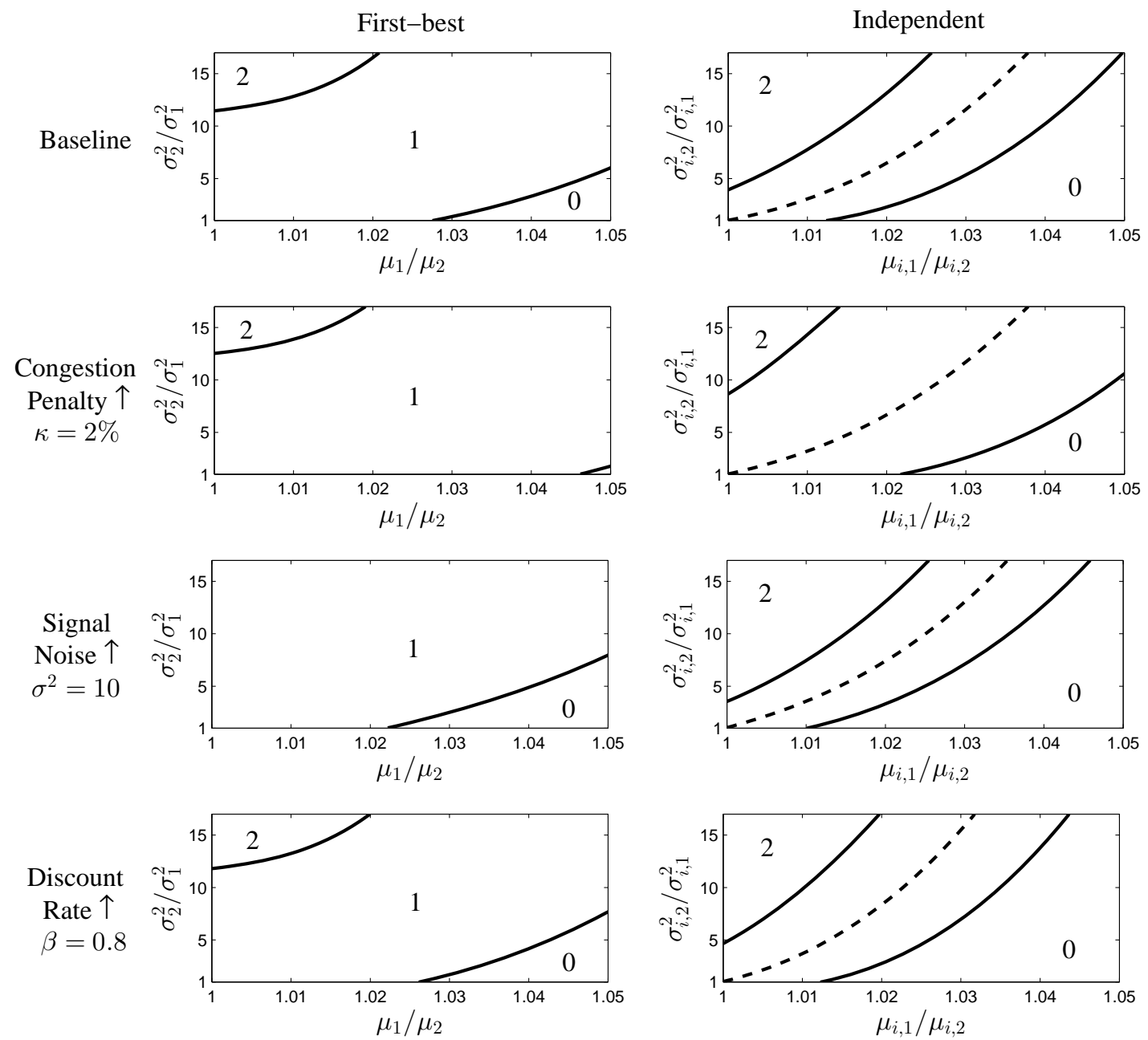

Figure 1: Equilibrium Site Choices. Baseline parameter values are: $\mu_{2}=\mu_{i, 2}=50, \sigma_{1}^{2}=$ $\sigma_{i, 1}^{2}=3, \kappa=0.5$ and $\sigma^{2}=2 ; \mu_{1}$ and $\mu_{i, 1}$ are varied between 50 and $52.5 ; \sigma_{2}^{2}$ and $\sigma_{i, 2}^{2}$ range between 3 and 48. Left-hand panels illustrate site choices under the first-best. Right-hand panels illustrate optimal site choices for independent fisherman. The regions 0,1 , and 2 denote where it is optimal for 0,1 , or 2 fishermen to explore the uncertain site 2 . The dashed line in the right-hand side panels denotes the set of beliefs where $a_{i}+a_{-i}=1$. 

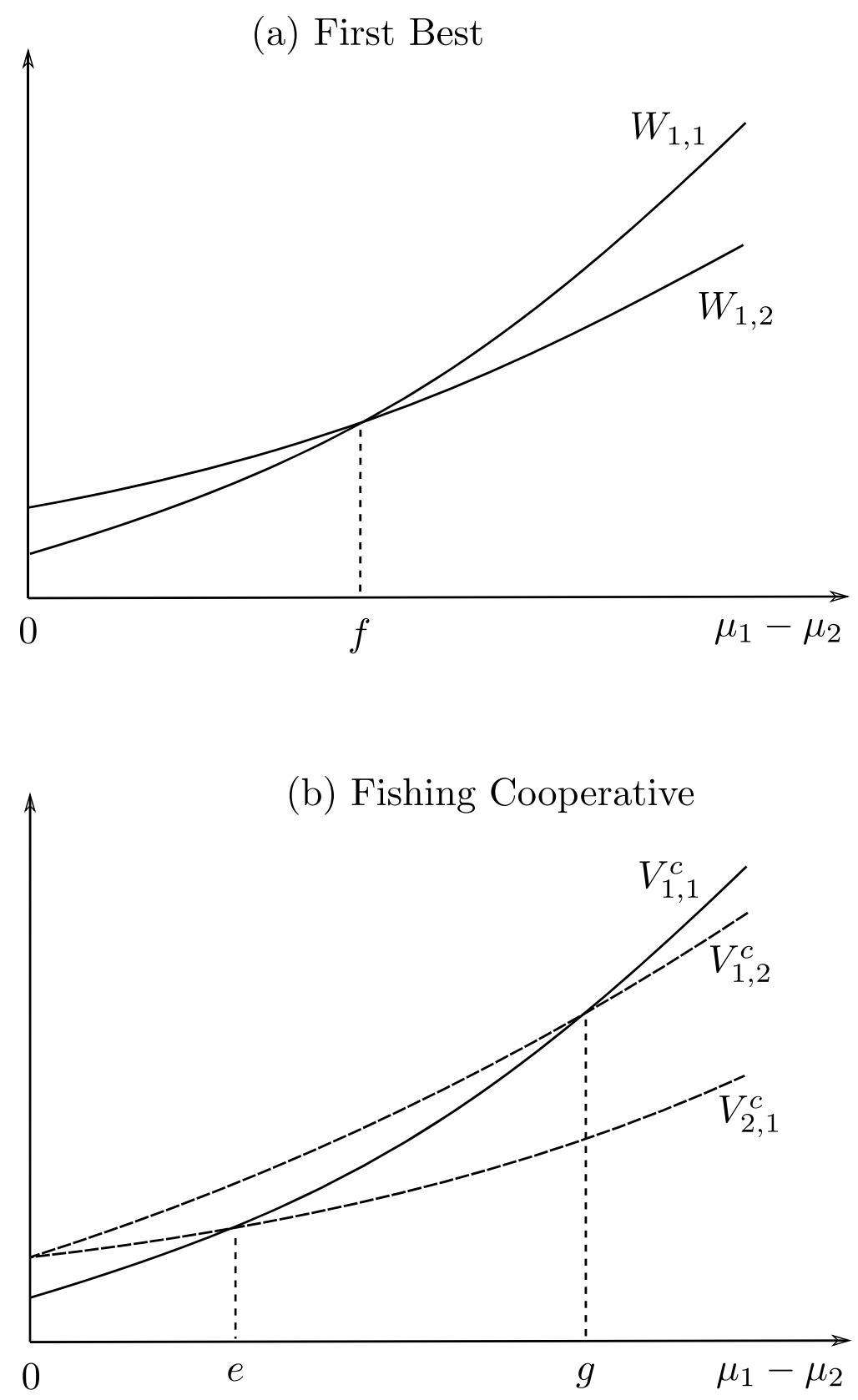

Figure 2: Expected Payoffs for Coop-Members and Under First-Best. The horizontal axis (both panels) is the perceived cost of gathering information at site 2. Panel (a): $W_{1,1}$ illustrates the expected payoff when both fishermen fish at site $1 ; W_{1,2}$ illustrates the expected payoff when one fisherman fishes at sites 1 , the other at site 2. Panel (b): $V_{1,1}^{c}$ illustrates the expected payoff for a coop member when both fish at site $1 ; V_{\text {explore }}^{c}$ illustrates the expected payoff for exploring coop member; $V_{\text {exploit }}^{c}$ illustrates the expected payoff for exploiting coop member. 


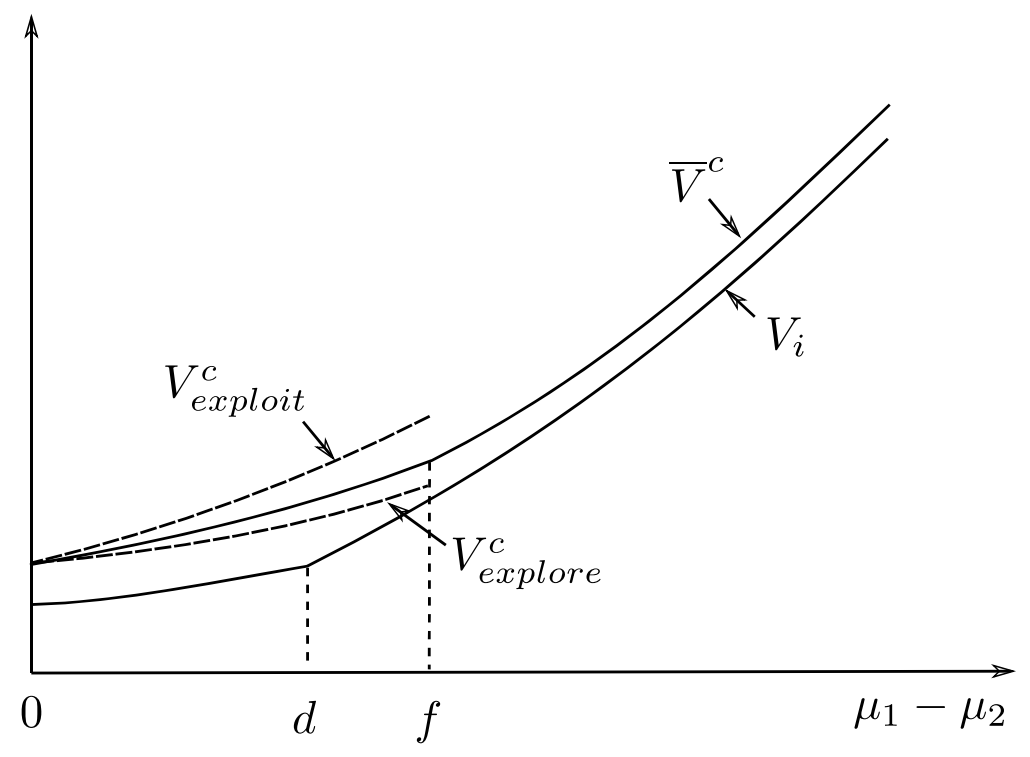

Figure 3: Independent Fishermen and Coop-Member Expected Payoffs. The horizontal axis is the perceived cost of gathering information at site 2. $V_{i}$ illustrates the expected payoff for an independent fisherman; $\bar{V}^{c}$ illustrates the average expected payoff to a coop member under first-best site choices; $V_{\text {explore }}^{c}$ and $V_{\text {exploit }}^{c}$ illustrate the expected payoff for an exploring and exploiting coop member paid under the piece-meal $(\alpha>0)$ under first-best site choices. 


\section{Extended Appendix}

This appendix shows how the model of section 3 can be extended to consider risk averse preferences. We repeat the derivation of PBNE site choice strategies under risk aversion, compare equilibrium search strategies of independent fishermen with first best policies, and discusses some implications for site choice in a fishing cooperative. A complete analysis of the combined effects of risk aversion and costly information acquisition and sharing in fishing cooperatives is reserved for future work.

\section{A Risk aversion}

Assume preferences follow a negative exponential utility function,

$$
U(s)=1-\exp (-\lambda s)
$$

where $s$ is the realized payoff and $\lambda>0$ is a risk preference parameter. ${ }^{14}$

\section{B Bayesian Nash Equilibrium}

This sections solves the date $t_{2}$ Bayesian game for independent, expected utility maximizing fishermen. Risk neutrality is a special case of this solution where $\lambda \rightarrow 0$. Suppose fisherman $i$ chooses site $j$ in the first fishing period. Consider the following date $t_{2}$ strategy profile (we assume both fishermen play similar strategies),

$$
\begin{cases}\text { fish site } j & \text { if } s_{i, j}>s_{i}^{U} \\ a_{i}^{\prime} \in(0,1) & \text { if } s_{i}^{L} \leq s_{i, j} \leq s_{i}^{U} \\ \text { fish site } i & \text { if } s_{i, j}<s_{i}^{L}\end{cases}
$$

We solve for the thresholds $s_{i}^{U}, s_{i}^{L}, s_{-i}^{U}$, and $s_{-i}^{L}$ from (16), which separate feasible signals into regions where pure and mixed strategies are played. There are four possible scenarios to consider depending on the period 1 site choices. We present the calculations for the case where both fishermen fish site 1 in the first fishing period. The analysis of the remaining cases follows analogously and is not repeated.

We begin by specifying how fishermen form beliefs about beliefs. Since both fishermen fished site 1 in the first period, $i$ 's belief about $-i$ 's private information should be a function

\footnotetext{
${ }^{14}$ The negative exponential function has several attractive properties. It exhibits constant absolute risk aversion. As $\lambda \rightarrow 0$, preferences are consistent with risk neutrality. Utility lies in the interval $(0,1)$. Finally, simple analytic expressions for expected utility exist.
} 
of $s_{i, 1}$, i.e., $i$ 's private information obtained from fishing site 1 . The best information available about $-i$ 's beliefs comes from $i$ 's updated beliefs. As such, each fisherman believes they share the same updated beliefs about sites 1 and 2 .

Suppose $s_{-i}^{U}$ and $s_{-i}^{L}$ exist such that the representative fisherman's counterpart plays the strategy outlined in equation (16). For the representative fishermen with $s_{i, 1} \in\left[s_{i}^{L}, s_{i}^{U}\right]$ to play a mixed strategy in $t_{2}, a_{i}^{\prime} \in(0,1)$, it must be the case that, based on his conjecture about his counterpart's strategy, he is indifferent between fishing site 1 and site 2 . Setting the expected utility of fishing these sites equal and solving for $a_{-i}^{\prime}$ finds,

$$
a_{-i}^{\prime}=\frac{\mu_{i, 1}^{\prime}-\mu_{i, 2}^{\prime}-\frac{\lambda}{2}\left(\sigma_{i, 1}^{2^{\prime}}-\sigma_{i, 2}^{2^{\prime}}\right)-\kappa+2 \kappa \operatorname{Pr}\left(s_{-i, 1}<s_{-i}^{U} \mid s_{i, 1}\right)}{2 \kappa \operatorname{Pr}\left(s_{-i}^{L} \leq s_{-i, 1} \leq s_{-i}^{U} \mid s_{i, 1}\right)} \quad \forall s_{i, 1} \in\left[s_{i}^{L}, s_{i}^{U}\right]
$$

Using the same method, we can calculate the mixed fishing strategy for the representative fisherman, $a_{i}^{\prime}$.

In a BNE, each player's action must be optimal subject to their Bayesian updated belief about the strategy of their rival. Using $a_{i}^{\prime}$ and $a_{-i}^{\prime}$, we derive four equations that define the parameters $s_{i}^{U}, s_{i}^{L}, s_{-i}^{U}$, and $s_{-i}^{L}$ that will satisfy a BNE.

The representative fisherman believes that his counterpart is indifferent between mixing and fishing site 1 when $a_{-i}^{\prime}$ exactly equals one (his counterpart knows that this is the representative fisherman's belief). For site 1 to be strictly dominant, it must be that it is still preferred even under the worst case (when both fish the site). Using this fact, the belief updating rules, and the strategy profile in equation (16), the representative fisherman's upper signal threshold $s_{i}^{U}$ must satisfy

$$
s_{i}^{U}=\frac{1}{1-\theta_{i, 1}}\left\{\left[\mu_{i, 2}-\theta_{i, 1} \mu_{i, 1}\right]-\frac{\lambda}{2}\left[\sigma_{i, 2}^{2}-\theta_{i, 1} \sigma_{i, 1}^{2}\right]+\kappa\right\}
$$

where $\theta_{i, 1}=\sigma^{2} /\left(\sigma^{2}+\sigma_{i, 1}^{2}\right)$.

Similarly, fisherman $i$ believes his counterpart is indifferent between mixing and fishing site 2 when $a_{-i}$ exactly equals zero (his counterpart knows that this is the representative fisherman's belief). For site 2 to be strictly dominant, it must be that it is still preferred even under the worst case (when both fish the site). Using this fact and given the strategy profile, the representative fisherman's lower signal threshold $s_{i}^{L}$ must satisfy

$$
s_{i}^{L}=\frac{1}{1-\theta_{i, 1}}\left\{\left[\mu_{i, 2}-\theta_{i, 1} \mu_{i, 1}\right]-\frac{\lambda}{2}\left[\sigma_{i, 2}^{2}-\theta_{i, 1} \sigma_{i, 1}^{2}\right]-\kappa\right\} .
$$


Using the same argument, we construct the following for fisherman $-i$ :

$$
\begin{aligned}
& s_{-i}^{U}=\frac{1}{1-\theta_{-i, 1}}\left\{\left[\mu_{-i, 2}-\theta_{-i, 1} \mu_{-i, 1}\right]-\frac{\lambda}{2}\left[\sigma_{-i, 2}^{2}-\theta_{-i, 1} \sigma_{-i, 1}^{2}\right]+\kappa\right\} \\
& s_{-i}^{L}=\frac{1}{1-\theta_{-i, 1}}\left\{\left[\mu_{-i, 2}-\theta_{-i, 1} \mu_{-i, 1}\right]-\frac{\lambda}{2}\left[\sigma_{-i, 2}^{2}-\theta_{-i, 1} \sigma_{-i, 1}^{2}\right]-\kappa\right\} .
\end{aligned}
$$

The thresholds that satisfy the BNE $, s_{i}^{U}, s_{i}^{L}, s_{-i}^{U}$, and $s_{-i}^{L}$, defined by equations (18) (21), must simultaneously hold.

\section{Results}

Suppose fishermen have less information about the true payoff at site 2. A decision to gather information at an uncertain site now carries an added current period cost in the form of exposure to risk. On the other hand, with multiple fishing periods, active learning reduces uncertainty, which reduces exposure to future risk. The net effect of risk aversion on the demand for information is therefore ambiguous in a dynamic setting (Freixas and Kihlstrom (1984)).

Figure 4 reports the first-best and PBNE policies for a subset of beliefs under negative exponential utility (for $\lambda \rightarrow 0$ and $\lambda=0.1$ ), and the baseline parameters. ${ }^{15}$ The units of the axes are unchanged and hold the same meaning as used throughout the paper.

A first observation is that there is less investment in information under risk averse preferences. The results show, at most, a single visit to uncertain site 2 is made under the first-best policy. The maximum cost warranting an investment in information is 1.03, or a $3 \%$ reduction in the expected payoff. Independent fishermen are also less willing to expose themselves to risk; gathering information at site 2 is optimal over a smaller range of the belief space.

A second observation is non-monotonicity in the demand for information. At low levels of uncertainty, an increase in the cost of gathering information can be offset by an increase in information value. As payoff variance increases, however, the disutility associated with high risk payoffs outweighs information value. The boundary between regions of the belief space, which may be interpreted as payoff mean and variance indifference curves, becomes negatively sloped; fishermen are willing to expose themselves to high risk payoffs only if the utility cost of learning is small.

As with risk neutral preferences, investments in information under the PBNE policy is in-

\footnotetext{
${ }^{15}$ First-best utility is calculated as $U=1-\exp \left(-\lambda\left(s_{i}+s_{-i}\right)\right)$. Our selection of $\lambda$ does not qualitatively change our results.
} 

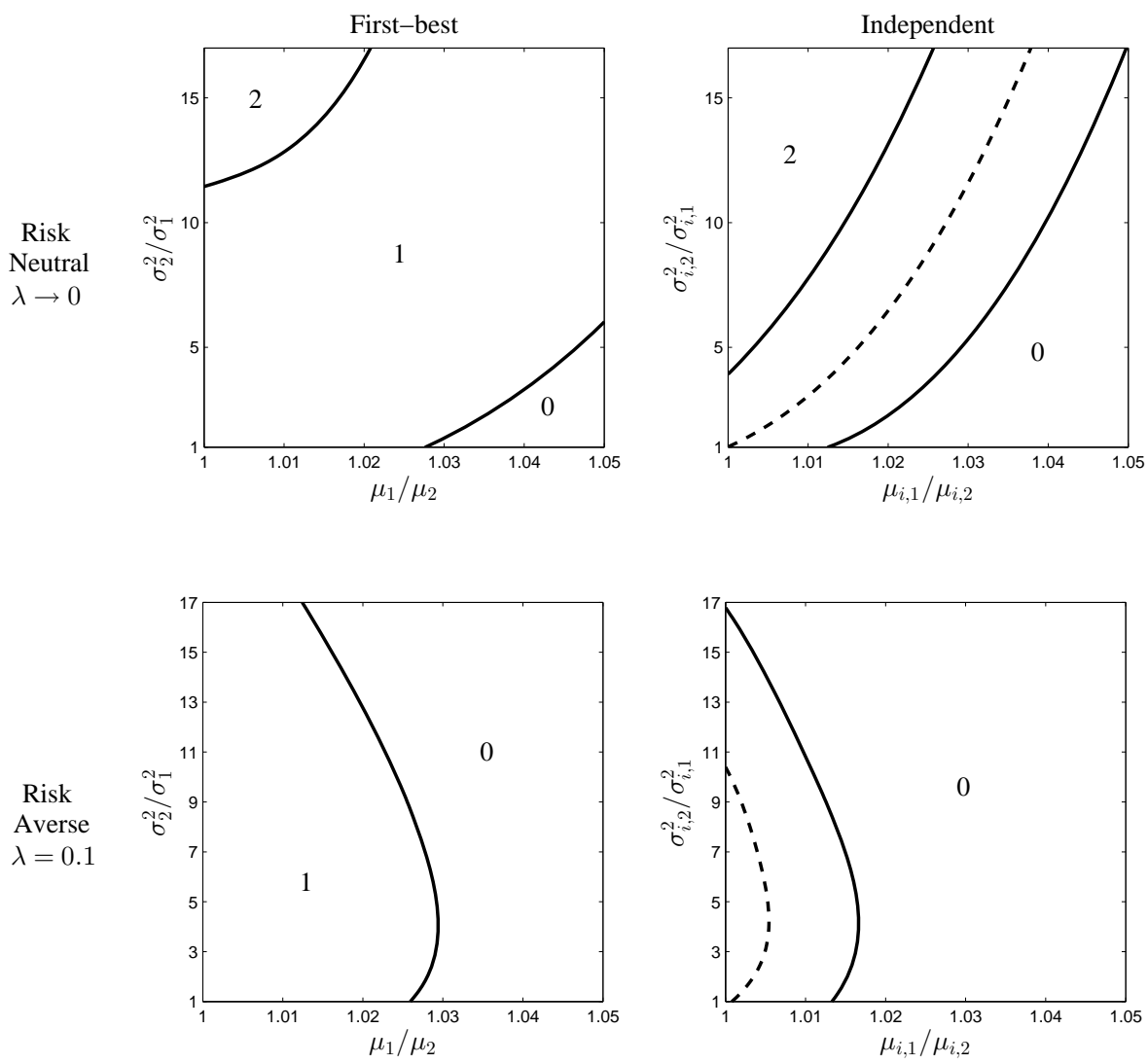

Figure 4: Equilibrium Site Choices Under Risk Neutrality and Risk Aversion. Baseline parameter values are: $\mu_{2}=\mu_{i, 2}=50, \sigma_{1}^{2}=\sigma_{i, 1}^{2}=3, \sigma^{2}=2$, and $\kappa=0.5 ; \mu_{1}$ and $\mu_{i, 1}$ are varied between 50 and 52.5; $\sigma_{2}^{2}$ and $\sigma_{i, 2}^{2}$ ranges between 3 and 48. The left-hand side panels denote the optimal fishing strategy under the first-best. The right-hand side panels denote the optimal fishing strategy under independent fishermen. The regions 0,1 , and 2 , denote where it is optimal for 0,1 , or 2 fishermen to explore the uncertain site 2 . The dashed line in the right-hand side panels denotes the set of beliefs where $a_{i}+a_{-i}=1$.

efficient. Relative the the first-best policy, independent fishermen over-invest in information in some regions of the belief space, and under-invest in others.

Risk preference also affects the tension between members of the cooperative. Recall that under risk neutrality, for any $\alpha>0$, each coop member will prefer that some other member be responsible for costly investment in information.

Consider the case where $\kappa=0$; we wish to focus on the value of information over coordination of fishing activities to avoid congestion costs. Using the piece-meal remuneration described in section 3.4, let $\pi_{1,2}=\frac{1}{2}\left(s_{i, 1}+s_{-i, 2}\right)+\frac{\alpha}{2}\left(s_{i, 1}-s_{-i, 2}\right)$ and $\pi_{2,1}=$ $\left.\frac{1}{2}\left(s_{i, 1}+s_{-i, 2}\right)-\frac{\alpha}{2}\left(s_{i, 1}-s_{-i, 2}\right)\right) . \quad \pi_{1,2}$ and $\pi_{2,1}$ are random variables. Using the convolution of $s_{i, 1}$ and $s_{-i, 2}$, we can derive the mean and variance for these random payoffs and 
compute the corresponding expected utilities. Then, expected utility takes the form,

$$
E U\left[\pi_{j, k}\right]=1-\exp \left(-\lambda\left[E\left[\pi_{j, k}\right]-\frac{\lambda}{2} \sqrt{\operatorname{Var}\left[\pi_{j, k}\right]}\right]\right) \quad \text { for } j, k=\{1,2\}
$$

Given our assumptions on beliefs, $E\left[\pi_{1,2}\right]>E\left[\pi_{2,1}\right]$ and $\operatorname{Var}\left[\pi_{1,2}\right]<\operatorname{Var}\left[\pi_{2,1}\right]$. This implies that $E U\left[\pi_{1,2}\right]>E U\left[\pi_{2,1}\right]$. As such, for any level of risk preference $(\lambda \in(0, \infty))$ the tension between fishermen remains with each preferring that some other member makes the costly investment in information. 